\title{
COLLABORATION BETWEEN GENERATIONS IN ALTERNATE REALITY GAMES
}

David Kaufman and Simone Hausknecht

There has been limited research that explores intergenerational play especially in the context of digital games. In this paper, we explore the idea of using alternate reality games (ARGs) for collaborative learning between players from different generations. ARGs provide an opportunity for engaging, immersive, gameplay where collaboration is often required. First, we describe the role of serious games for older adults and intergenerational learning. Second, we describe ARGs as a new type of game for collaborative learning and articulate a series of design considerations for creating ARGs for intergenerational learning. These games focus on ways to promote collaboration by blurring the boundaries between real life and the game, utilizing collaborative storytelling, and using demographic-specific mixed media. 


\section{Introduction}

Intergenerational contact is important for the well-being of all generations. For example, previous studies have found benefits in intergenerational relationships such as a higher sense of emotional well-being (Weintraub \& Killian, 2007) and life satisfaction (Meshel \& Mcglynn, 2004) in older adults, and a reduction of ageism and lower depression rates in younger generations (Ruiz \& Silverstein, 2007). Yet intergenerational contact is becoming increasingly limited due to age segregation through institutions, culture, change in housing situations, and other factors (Hagestad, \& Uhlenberg, 2005). Relationships between youth and their grandparents have been found to provide a mutual beneficial exchange of social support (Moffatt, David, \& Baecker, 2012).

Digital games, for example, are increasingly being studied as media to help establish and maintain intergenerational contact (Aarsand, 2007; Chua et al, 2013) where they can act as learning environments (Siyahhan, Barab, \& Downton, 2010). Alternate reality games (ARG) represent one type of game that has this type of environment and potential for increasing intergenerational interaction and learning, but has had limited research conducted around such topics. An alternate reality game is a transmedia experience spanning various types and forms of media that combines collaborative storytelling with game elements and uses real life as a medium (Bonsignore et al, 2013).

\section{Digital games and older adults}

De Schutter \& Abeele (2015) suggest a gerontoludic manifesto in designing and researching games for older adults where they put forth a number of adages. Firstly, they suggest focusing on "playfulness over usefulness". Here play is seen as a valuable activity. Older adults should not need an excuse to play, but instead researchers should honor play as an expression and valuable activity. The next adage they suggest is "growth over decline". Aging is a process of both growth and decline; however, in our society the decline is often focused on more than growth when it comes to the older population. Personal growth and challenge are important to older adults and, thus, games for older adults could utilize this instead of focusing on how to stop decline (De Schutter \& Abeele, 2015). Finally, they articulate that games research and design should concentrate on "heterogeneity over stereotyping". Older adults who are gamers have a diversity of preferences, experiences, and physiological health. As such, there still needs to be consideration for accommodations when needed. Lynch and Vitols (2015) add to the manifesto by suggesting that gaming for selfexpression and creativity should also be included while a final addition is the opportunity for community, such as in massively multiplayer online role-playing games (MMORPGs). Multiplayer games contain players who range in age where they can form valuable communities. Other social gam- ing experiences can also contribute to a sense of community as seen in research on a Wii Bowling tournament (Schell, et al., 2016), which found that game play created increased social connections. A follow-up study of this experience showed that many of these connections continued to be valuable additions to people's lives, and some groups maintained their cohesiveness long after the tournament was over (Hausknecht, Schell, Zhang, \& Kaufman, 2015).

When it comes to game-based learning for older adults there is often a focus on cognitive stimulation, or brain training. However, this is aligned more with the reductionist view versus the adages suggested by De Schutter \& Abeele (2015). Instead, we are suggesting an approach to game design that, firstly, integrates the knowledge and experience of older adults and what they can share with youth and vice versa. Secondly, we are considering learning as collaborative. In designing games for these types of interactions, the focus is on experiences and challenges that can be overcome with collaborative group efforts.

We suggest that to address the principles of the gerontoludic manifesto proposed by De Schutter and Abeele (2010) and contribute to this discussion when conducting research and design on intergenerational learning, it is imperative not to focus on what the young person can do for the older person, but instead to frame the interaction as finding 
the best approach to create an environment where reciprocal learning and collaboration can occur? Thus, how can the positive aspects of age, such as the possible knowledge gained through time, be used in ways that can benefit younger learners' knowledge construction? Mutually, in what ways can younger learners' experiences and understandings contribute to the knowledge construction of older adults? The rich variety of perspectives of multiple age groups could provide a fertile ground for learning. We argue that a style of game, alternate reality games, may be utilized for these purposes and suggests possible design approaches to enhance the intergenerational collaborative experience.

\section{Serious Games and intergenerational learning and interaction}

Intergenerational learning can be considered learning that occurs between one or more generations (e.g., parent/child, grandparent/grandchild, youth/older adult). Traditionally, research and theory on intergenerational learning has focused on unidirectional knowledge acquisition, usually from the older person to the young; however, these ideas have evolved to view intergenerational learning as a mutual sharing of the learning experience (Kenner et al., 2007). For example, the European Network for Intergenerational Learning (2015) describes it as "a learning partnership based on reciprocity and mutuality involving people of different ages where the generations work together to gain skills, values and knowledge." Thus, the emphasis is on the reciprocal relationship of learning. Furthermore, if perceived through a social constructivist lens, it is the knowledge construction that occurs between two different age cohorts. The emphasis is on a collaborative exchange, and not a top-down system. Consequently, intergenerational learning designs should consider the collaborative space and interactive affordances of the game. Various benefits of intergenerational learning have been reported specifically from psychologists where it has been found to have beneficial effects on well-being; however, it has also been shown to be useful in creating a reflective environment through the exchange of differing experiences and perspectives (Demichelas et al., 2015).

Digital games can serve as interactive environments that facilitate these types of intergenerational interactions. Several studies (Aarsand, 2007; Siyahhan, Barab, \& Downton, 2010; Chua et al. 2013) have examined the possibility of increasing and developing intergenerational relationships using digital games with mixed success in regards to collaboration. Aarsand (2007) conducted an ethnographic study of families with children aged 8 to 10 years old and found that the digital divide was used in various ways to support intergenerational interaction during gameplay. The children often dominated the game control when playing with parents and grandparents since they had increased experience with the technology. However, this did not appear to affect the relationships negatively, but, instead, resulted in a positive exchange where the child was the knowledgeable teacher. As pointed out by Aarsand (2007), although the learning seems mainly asymmetrical, it also allows grandparents and parents to engage in a shared activity space. Chua et al (2013) conducted a longitudinal study on the perceptions of older adults and youth on playing a digital game. Older adults were recruited from two seniors' centres in Singapore where the study took place and were paired with a youth partner. This study showed the positive results of reducing ageism through intergenerational play versus simply interacting.

Digital games focused on intergenerational collaboration have also been studied in educational settings. Siyahhan, Barab \& Downton (2010) conducted a study on an afterschool program called Family Quest that used a 3D immersive educational game (Quest Atlantis) played between 9-13 year olds and their parents. Positive results were found for parent-child relations in general but the dynamics varied between each pair. Siyahhan, Barab \& Downton (2010) have suggested designing games that are meaningful to participants, creating a space where both players will be motivated by similar intentions, and promoting a game narrative that challenges traditional norms.

The above studies outline the possibility of using digital games to bridge generations and provide opportunities for intergenerational interaction. However, there are a limited number of studies aimed at designing for intergenerational collaboration. In the above studies, one important area that emerged was the varying roles and negotiations of these roles against traditional norms. To enhance collaboration and allow for a more reciprocal learning experience, specific games designed for intergenerational collaboration may be valuable. One style of game that has the potential for being designed as a collaborative space for fostering learning and 'pushing back' on traditional roles is alternate reality games. We discuss these below.

\section{Alternate Reality Games}

Alternate reality games (ARGs) are a form of game that combines narrative, collaborative storytelling, 
mixed media, and puzzle solving. ARGs are an immersive form of game in which the narrative and a series of puzzle pieces make up the core components (Connolly, Stansfield, \& Hainey, 2011). The game takes place over a mixed media environment, which could include websites, phone calls, real life environments, newspapers, etc. Additionally, ARGs use media and narrative to blend the player's real life and game life creating a pervasive environment. Thus, ARGs attempt to blur the lines between reality and fiction (Benford et al, 2006).

ARGs start with some form of a "rabbit hole." This is the first point of contact between a player and the game and it guides the player to the game. Typical rabbit holes include a random link on a website, a QR code on a poster, or any clue that is deliberately left for players to discover the game. The puzzle pieces within the game are often designed to be solved through group efforts and collaboration between the players, for example, clues may be left in various cities or require different skill sets. A "puppet master" is the person who orchestrates the events and guides players through the unfolding narrative. The storyline itself has a certain flexibility as players discover fragments of the narrative throughout their gameplay and share their interpretations with others in the group, creating a collaborative story (Bonsignore et al. 2012).

The narrative of ARGs has two layers, the macro or canonical trajectory that the designer creates, and the micro or participant trajectory that the player creates (Benford et al., 2006). It is the designers' decision on how much influence the players have over the narrative by creating gaps and points of convergence between the canonical and participant trajectories (Bosignore, et al, 2014). To explore the affordances of ARGs for collaboration and interaction, a more thorough examination is presented below using several exemplar games to illustrate the key design features that ARGs include; in particular, these include an immersive environment, collaborative storytelling, puzzle pieces, pervasive gameplay by blurring reality and game play, and counterfactual thinking.

\section{Pervasive gameplay, blurring the lines}

Traditional video games often create a "magic circle" where the player knows they are in the game space and it is clear where the game ends and real life begins (Adams, 2013). Yet ARGs sometimes deliberately manipulate this aspect, creating a pervasive environment. Part of the immersive ability of ARGs involves this blurring of the lines between reality and fantasy by interweaving the narrative with the real world (Whitton et al. 2014). Collaboration can occur with an online player who has tracked their progress using an online map of the city. Players can communicate with each other and the online players could choose to help or hinder the efforts of the street player. Reality can be blurred by using live actors and the city as a game environment. Players do not always know whether people in the streets are actors or members of the general public and this feature could be used by designers to increase a game's pervasiveness (Benford et al., 2006). The advantages of blurring reality is that a pervasive interactive experience can be created. However, this same aspect could also cross the comfort levels of some players. A balance of allowing players to feel safe and yet still immersed may need to be carefully considered in future ARG designs, particularly for youth and older adults where safety is sometimes of increased concern.

\section{Alternate reality games for learning}

Several ARGs have been designed for educational purposes (e.g., Arcane Gallery of Gadgetry and Tower of Babel). One example is the Arcane Gallery of Gadgetry (AGOG), an ARG designed for a youth demographic in an educational setting (Bonsignore et al., 2012). This ARG focuses on the US Patent Office, which was a hub of innovation between 1836 and 1932. The game required students to use inquiry-based learning to examine history. The story starts with cryptic messages and a questioning of history, since history is created by the perspectives of the people who write about it (Bonsignore et al., 2012). From here students play the role of being part of a secret society in which they must examine historical texts that were recently discovered to see if they are accurate. Bonsignore et al (2012) used a variety of design strategies including a pervasive transmedia interface, integrative participatory narrative, a blended hybrid story world, player participation and authenticity. Bonsignore and her design team attempted to create designed experiences, versus using the game to deliver content. Thus, it attempted to get the students to question history and make their own interpretations by providing gaps and inaccuracies.

The first iteration included sixty 13-15 year old students, with 55 playing consistently. It took place over two weeks during a history class. Bonsignore et al (2012) used a multi-method case study approach to study game play. Study results suggest that the game was an engaging collaborative experience where students needed to negotiate meaning. Even though more studies are needed, the researchers came away with a sense that the design allowed history to 'come alive' through the fun interactive environment (Bonsignore et al., 2012). 
The rich narrative and immersive quality of ARGs provide a possible situation where intergenerational collaboration could occur through an exchange of perspectives and negotiation with the game. Furthermore, the flexibility and adaptability of designs can provide a unique opportunity to address the heterogeneity while maintaining accessibility concerns. The focus on narrative in the games often allows for deep problem-solving techniques and the imaginative power of counterfactual thinking (Bonsignore et al., 2012). Such environments could create opportunities for different age groups to be immersed together. However, to harness the potential of these forms of games for intergenerational collaboration, an exploration of design considerations is needed.

\section{Design Considerations}

There have only been a few alternate reality game designs that have considered these game spaces for intergenerational collaboration and learning (e.g., Hausknecht, 2015; Costa \& Velosa, 2014). This section will examine and discuss possible design approaches for intergenerational collaboration within the game genre of ARGs. Our approach also attempts to address the concerns of the gerontoludic manifesto (De Schutter \& Abeele, 2015) by focusing on creating a reciprocal learning experience within play. Thus, the design approach utilizes the perspectives of both age cohorts-youth and older adults-to challenge their understanding of the world. This exchange of learning is situated within the rich environment of the game narrative and play mechanisms.

\section{Crossing game trajectories for collabo- ration}

In this chapter, we have argued that digital games can create an opportunity to bring intergenerational players together (Aarsand, 2007; Siyahhan, Barab, \& Downton, 2010; Chua et al. 2013); however, many games are designed such that only one player can take on an expert role or one player may dominate due to traditional norms (Aarstand, 2007, Siyahhan, Barab, \& Downton, 2010). This leaves limited room for collaborative gameplay or perceptions of reciprocal learning (Aarsand, 2007, Siyahhan, Barab, \& Downton, 2010). One way to design ARGs to overcome this is by creating specific game trajectories that require collaboration to move the game forward.
Benford (2009) suggests that pervasive games, such as ARGs, can use a framework of trajectories as a design and research approach. The trajectories in a game involve the canonical trajectory and participant trajectory. The canonical trajectory is the experience and points in time that the designer intends the player to go through (Benford et al., 2006). However, within a game the players are able to also create their own participant trajectory that strays from and adds to the canonical trajectory depending on how open the game structure and narrative is. For example, as players figure out what elements are part of the game and which are not, they will move along their own path or trajectory and intersect with the canonical trajectory at points when their actions map to the actual game elements. Part of the success of an ARG is in the management of the tension between canonical and participant trajectories (Benford et al., 2009). Allowing players to stray too far from the canonical trajectory may cause play to be confusing, while forcing players to always stay on the canonical trajectory may make a game boring. The flexibility to move throughout the game environment and 'come and go' from the canonical trajectory may create excitement for players as they discover the game's plotline and lead their own explorations.

We suggest that these ideas can be expanded upon when creating ARGs to support intergenerational collaboration. For example, when creating an ARG for both youth and older adults, one design strategy might be to create a single canonical trajectory through the game, thereby forcing both generations to participate in the same elements of game play. Yet this could be challenging since the same game elements may be too difficult or boring to one of the two demographics, or one player may become the expert throughout. An alternative strategy may, instead, involve designing multiple canonical paths though the game. There could be, for example one canonical trajectory for each generation. This path could be designed to be of specific interest to one of the two demographics, thus increasing interest in the game. To encourage collaboration and interactions between the generations, canonical paths through the game could then be designed to converge at various points. Interaction between players from each demographic could be necessary for further progression in the game. For example, players may need to come together to move the game forward, similar to finding different pieces of a puzzle and bringing them together and figuring out how they fit. Although there is hope that both players will collaborate when they are along the same trajectories, this divergence and convergence specifically requires both parties to be actively engaged in gameplay. Another approach may involve designing two different trajectories where players need the help of another at various points in order to progress along their own trajectory; one person may be considered an expert that can help out the 
other player at a certain point. For example, youth players may have to solve puzzles about World War II where older adults that are potentially subjectmatter experts (by experiencing the war period firsthand) can help them progress on their path. Then the role of expert could change in the next set of puzzles.

\section{Crossing game trajectories with real life trajectories}

Previous intergenerational game studies have suggested the inclusion of 'meaningful topics' within games (Siyahhan, Barab, \& Downton, 2010). Rich learning and discourse can occur when learners share multiple and varying perspectives (Stahl, 2004). One way to create these experiences is through the incorporation of cohorts' real life trajectories and history into the game.

With this in mind, puzzle pieces and clues within ARGs could be used to leverage differences based on diverse cohort understanding. We are not suggesting stereotyping all people of a cohorts' experience. To the contrary, a person's memory and perspective of historical events could be used to generate meaningful discussions across generations. For example, designing a game narrative that takes players back to 9/11 and the terrorist attacks on the World Trade Center in the United States may provide a point in players' real life timeline where they have specific experiences and knowledge to share. Thus, in using 9/11 as a narrative focal point, those born in the 1980 or earlier may remember the difference in security and governmental security measures. However, for those born after this point in time, their experience is a world that has always been this way. Both generations may be able to share their differing perspectives as part of the ARG.

Games designed with narrative that incorporate issues relevant to the players' lives allow for meaningful discussions to occur (Siyahhan, Barab, \& Downton, 2010). Incorporating meaningful experiences could be achieved by finding narrative that intertwines with topics of importance that cross both cohorts' timelines as suggested above, which leaves opportunity for sharing perspectives and reconstructing understanding. These may be very broad such as perspectives on fundamental human rights or issues that expand across time, such as woman's rights.

Another possibility for utilizing the cohort effect is through the types of clues and codes used in an ARG. A person of a certain generation may be able to recognize Morse code (not necessarily read it), while a younger cohort may understand how Snap- chat works and may see a clue embedded there more easily. Thus, a combination of leaving clues in recognizable forms and media for the two generations may help to keep the momentum of two players requiring each other's assistance to complete the game. This aligns two separate canonical trajectories where hopefully a variety of prior knowledge is required, increasing the likelihood of multiple experts throughout.

A final point on cohort effects is the differences in understanding of what play is (Brown \& De Schutter, 2016). Brown \& De Schutter noted that cohort experience with play and digital games may be different and designs could consider such differences. For example, different age cohorts may have had certain games that were popular in their childhood/youth that were enjoyed and easily recognized (Brown \& De Schutter, 2016). These may shape their perceptions of play. Each player will be bringing their own experience of play to the ARG which will require negotiation during their collaborative interaction. Thus, there may be a reciprocal learning of what play means. For example, if a player is used to ludic style puzzle games such as Tetris while another has been involved with immersive Multiplayer narrative style games, the two may bring different skills and understanding to the game experience. Within the game, one player's understanding of play as fitting together of puzzle pieces and the other's understanding of an unfolding narrative, may leave opportunity for showing each other the excitement of the different styles. Brown \& De Schutter (2016) suggest that designers could also incorporate these effects by finding out which games were popular at different points in time.

\section{Collaborative Storytelling}

Alternate reality games provide the opportunity for knowledge construction through collaborative storytelling. As players attempt to make sense of the narrative pieces, they will also be adding to the narrative with their own understanding of the events (Bonsignore et al., 2014). ARGs provide the possibility for players to contribute to the game narrative, or at least feel like they do. Some games may use a thickly-plotted narrative where the players cannot veer too far off of the designed canonical trajectory, nor do they actually have much control over the plot. In these designs there is often a strong guiding force as players are directed through certain narrative points (Bonsignore et al, 2015). On the other hand, some ARGs are loosely designed leaving a lot of room for player input. This may create a less guided gameplay (Bonsignore et al., 2014). An appropriate balance could be particularly 
important within a game designed for players who may not have experience with these styles of gaming environments. Scaffolding may need to be carefully structured. Hausknecht (2015) suggests progressing in phases, easing players into the pervasive mixed media environment.

Furthermore, in learning environments there is often a need for player guidance from the start (Romero et al., 2012). Leaving the game too open may not work for all players, especially those with varying levels of experience and understanding that could easily occur with intergenerational games. However, guidance should not influence the narrative, the immersive nature, or the pervasiveness of the game negatively. Opportunities are available for just-in-time guidance from characters that push the narrative forward. Including guidelines within plot structure or even within clues may be a useful way to create continuity.

The narrative is a large feature in ARGs and it can guide characters in positive or negative directions. Thus, when considering this for a combined interaction of youth and older adults, the guiding structure of the narrative needs to be targeted to the desired collaboration and knowledge construction.

\section{Mixed media}

Alternate reality games are mixed media experiences that span different types of online and offline media. Depending on the media and the skill level of the players, this may pose difficulties. The experience may require a certain level of scaffolding and guidance to move the players between media types. Content may also need to be designed for different types of media given the differing skill levels (e.g., text messaging for older adults as it may be a new technology to them, but fine for young adults to reflect their interests). Or, one could design for the same media and suggest that the two demographics collaborate to help guide each other. At times, the younger person may utilize their skills and teach the older adults how to understand and use the new technology. As mentioned, one would not want this to be the game's entire focus as it would create a one directional approach to learning, yet this could still be a valuable learning and teaching approach at certain points in the game.

Another important aspect is the design of the rabbit hole and an ARG's main web site, if it has one. Intergenerational ARGs would need to be designed cautiously such that all players would be able to find the rabbit hole and main site and recognize them as such. Although traditional ARGs use rabbit holes for initial discovery, and then word of mouth starts to take hold, with a specific target audience, this may not be viable. Having an obscure entry point into the game would likely also not work for a range of diverse players. Thus, a design with a targeted audience will likely need an overt rabbit hole that explicitly guides players to the game. For example, after players agree to play, they could receive an email link that is clearly related to the game and denoted as the starting point. This may come back to understandings of play. If players have not experienced an ARG before, they may not immediately understand that 'anything' could be part of the game.

While working with youth, Bonsignore et al. (2012) found that having one main web site for sharing information (with multiple sub-pages) was easier in a learning environment with the cohort they were working with. Initial ARG designs may need to include plans for increased guidance where needed. For example, Hausknecht (2015) suggested incorporating characters who play as players and provide extra guidance where needed, while not ruining the flow of gameplay.

\section{Conclusion}

Alternate reality games could provide an opportunity for intergenerational collaboration and learning that can use varying skills and worldviews to contribute to game play. Their pervasive nature allows for engagement and a crossing of real life trajectories with game trajectories. This may allow for points where meaningful discussions can occur.

We believe that we have addressed some of the current concerns of game-based learning across the lifespan, particularly where older adults are concerned, by exploring games as a means for contributing to intergenerational learning that is reciprocal, playful, and meaningful to players. Such games may ease some of the tensions between experts and novices as seen in previous research on intergenerational play. It is hoped that the interaction within such games will also help to reduce ageism through playful interaction, shared experience, and negotiating different perspectives.

We have presented background research that describes ARGs as intergenerational learning environments, along with a series of design considerations that suggest the ways in which ARGs may fulfill this role. While grounded in the related literature, as well as our expertise in game study and design, these design considerations are certainly preliminary. We suggest that designers of educational systems and games consider them as a starting point for design explorations such that they can be verified, critiqued, and built upon as a part of future research. 


\section{Acknowledgements}

We wish to thank the Social Sciences and Humanities Research Council of Canada (SSHRC) and the AGEWELL Network of Centres of Excellence (NCE) for supporting this project financially.

\section{References}

AARSAND, P. A. (2007). Computer and Video Games in Family Life The digital divide as a resource in intergenerational interactions. Childhood, 14(2), 235-256.

ADAMS, E. (2013). Fundamentals of game design. Pearson Education.

BASAK, C., BOOT, W. R., VOSS, M. W., \& KRAMER, A. F. (2008). Can training in a real-time strategy video game attenuate cognitive decline in older adults?.Psychology and aging, 23(4), 765.

BENFORD, S., CRABTREE, A., REEVES, S., SHERIDAN, J., DIX, A., FLINTHAM, M., \& DROZD, A. (2006). The frame of the game: blurring the boundary between fiction and reality in mobile experiences. In Proceedings of the SIGCHI conference on Human Factors in computing systems, 427-436. ACM.

BENFORD, S., GIANNACHI, G., KOLEVA, B., \& RODDEN, T. (2009, April). From interaction to trajectories: designing coherent journeys through user experiences. In Proceedings of the SIGCHI Conference on Human Factors in Computing Systems (pp. 709-718). ACM.

BONSIGNORE, E., HANSEN, D., KRAUS, K., AHN, J., VISCONTI, A., FRAISTAT, A., \& DRUIN, A. (2012). Alternate Reality Games: platforms for collaborative learning. In Proceedings of the 10th International Conference of the Learning Sciences, ICLS 2012 (Vol. 1, pp. 251-258).

BONSIGNORE, E., MOULDER, V., NEUSTAEDTER, C., HANSEN, D., KRAUS, K., \& DRUIN, A. (2014, April). Design tactics for authentic interactive fiction: insights from alternate reality game designers. In Proceedings of the 32nd annual ACM conference on Human factors in computing systems (pp. 947-950). ACM.

BROWN, J. A., \& DE SCHUTTER, B. (2016). Game Design for Older Adults: Lessons from a Life Course Perspective. International Journal of Gaming and Computer-Mediated Simulations (IJGCMS), 8(1), 1-12.

CHUA, P. H., JUNG, Y., LWIN, M. O., \& THENG, Y. L. (2013). Let's play together: Effects of videogame play on intergenerational perceptions among youth and elderly participants. Computers in Human Behavior, 29(6), 2303-2311.

CONNOLLY, T. M., STANSFIELD, M., \& HAINEY, T. (2011). An alternate reality game for language learning: ARGuing for multilingual motivation. Computers \& Education, 57(1), 1389-1415.

COSTA, L., \& VELOSO, M. (2014). Alternate reality games and intergenerational learning. Conferênncia de Ciências e Artes dos Videojogos, IPCA, November 6-7, 2014. 
DEMICHELIS, C., FERRARI, M., ROZIN, T., \& STERN, B. (2015). Teaching for Wisdom in an Intergenerational High-School-English Class. Educational Gerontology, (ahead-of-print), 1-16.

DE SCHUTTER, B., \& ABEELE, V. V. (2015). Towards a Gerontoludic Manifesto.Anthropology \& Aging, 36(2), 112-120.

Eurpopean Network For Intergenerational Learning. (2015). What is IGL? http://www.enilnet.eu/

HAGESTAD, G. O., \& UHLENBERG, P. (2005). The social separation of old and young: A root of ageism. Journal of Social Issues, 61(2), 343-360.

HAUSKNECHT, S. (2015). Ancestors now: An ARG design for intergenerational play. In M. Romero (Ed.), Intergenerational learning, life narratives and games (Vol. 1, pp. 108-112). Québec: Centre de recherche et d’intervention sur la réussite scolaire (CRIRES).

HAUSKNECHT, S., SCHELL, R., ZHANG, F., \& KAUFMAN, D. (2015). Older Adults Digital Gameplay: A Follow-up Study of Social Benefits. In Information and Communication Technologies for Ageing Well and e-Health (pp. 198-216). Springer International Publishing.

JAFARINAIMI, N., \& MEYERS, E. M. (2015, February). Collective Intelligence or Group Think?: Engaging Participation Patterns in World without Oil. In Proceedings of the 18th ACM Conference on Computer Supported Cooperative Work \& Social Computing (pp. 1872-1881). ACM.

KENNER, C., RUBY, M., JESSEL, J., GREGORY, E., \& ARJU, T. (2007). Intergenerational learning between children and grandparents in East London. Journal of Early Childhood Research, 5(3), 219-243.

LO, H., NEUSTAEDTER, C. (in review). Collaboration in Real-Life escape rooms. In Proceedings of the Conference on Computer-Human Interaction 2016, ACM Press.

LYNCH, C., \& VITOLS, M. (2015). Response 1 to" Towards a Gerontoludic Manifesto". Anthropology \& Aging, 36(2), 121-123.

MESHEL, D., \& MCGLYNN, R. (2004). Intergenerational contact, attitudes, and stereotypes of adolescents and older people. Educational Gerontology, 30(6), 457-479.

MOFFATT, K., DAVID, J., \& BAECKER, R. M. (2012). Connecting grandparents and grandchildren. Connecting families: The impact of new communication technologies on domestic life, 173-193.

PLØHN, T. (2014). Pervasive Learning-Using Games to Tear Down the Classroom Walls. Electronic Journal of e-Learning, 12(3).

ROMERO, M., USART, M., OTT, M., EARP, J., \& DE FREITAS, S. (2012). Learning through playing for or against each other? Promoting collaborative learning in digital game based learning. Learning, 5(2012), 15-2012. 
RUIZ, S. A., \& SILVERSTEIN, M. (2007). Relationships with Grandparents and the Emotional Well $\square$ Being of Late Adolescent and Young Adult Grandchildren. Journal of Social Issues, 63[4], $793-808$.

SCHELL, R., HAUSKNECHT, S., ZHANG, F., \& KAUFMAN, D. (2016). Social benefits of playing Wii Bowling for older adults. Games and Culture, 11(1-2), 81-103.

SEBASTIAN, R., \& KINZIE, M. (2006). Development of Social Problem-solving Networks in the Interactive Web-based Game The Beast: A Qualitative Study. In World Conference on E-Learning in Corporate, Government, Healthcare, and Higher Education (Vol. 2006, No. 1, pp. 2350-2357).

SIYAHHAN, S., BARAB, S. A., \& DOWNTON, M. P. (2010). Using activity theory to understand intergenerational play: The case of Family Quest. International Journal of Computer-Supported Collaborative Learning, 5(4), 415-432.

STAHL, G. (2004). Building collaborative knowing. In What we know about CSCL (pp. 53-85). Springer Netherlands.

VOIDA, A., \& GREENBERG, S. (2012). Console gaming across generations: Exploring intergenerational interactions in collocated console gaming. Universal Access in the Information Society, 11(1), 45-56.

WARREN, S. J., DONDLINGER, M. J., MCLEOD, J., \& BIGENHO, C. (2012). Opening The Door: An evaluation of the efficacy of a problem-based learning game.Computers \& Education, 58(1), 397-412.

WEINTRAUB, A.P.C. \& KILLIAN T.S. (2007). Intergenerational programming: Older persons' perceptions of its impact. Journal of Applied Gerontology, 26(4), 370-384.

WHITTON, N., JONES, R., WILSON, S., \& WHITTON, P. (2014). Alternate reality games as learning environments for student induction. Interactive learning environments, 22(3), 243-252.

WISE, A. F., HAUSKNECHT, S. N., \& ZHAO, Y. (2014). Attending to others' posts in asynchronous discussions: Learners' online "listening" and its relationship to speaking. International Journal of Computer-Supported Collaborative Learning,9(2), 185-209. 